\title{
SPATIAL AND TEMPORAL ELEMENTS OF ANTICIPATION CONSISTENCY OF CHILDREN WITH GENERAL SPEECH RETARDATION
}

\author{
Anna Ivanovna Akhmetzyanova \\ Kazan (Volga Region) Federal University, \\ 18 Kremlyovskaya St., Kazan 420008, Republic of Tatarstan, Russian Federation
}

Received 2014-02-17; Revised 2014-02-25; Accepted 2014-04-17

\begin{abstract}
Psychologists of child care settings who are engaged in diagnosing psychological readiness of children for school education distinguished a group of individuals who are not sufficiently ready for the school education. At that, the overall assessment of the intellectual development of a child can be within the average age-related values. However, in the course of special research (defectological, neuropsychological), the attributes of certain extent of general speech underdevelopment are often detected. Thus, we face the task to identify the causes of school de-adaptation of children who have speech pathology. The article provides information on serious deviations of spatial and temporal elements of anticipation consistency of children with speech pathology; analyzes the indexes, which describe the voluntariness of mental activitythe ability to control consciously one's actions and mental processes. It was revealed that the typical attribute of children with general speech underdevelopment was insufficient self-control at fulfillment of tasks; they failed to follow carefully the rules and showed dominance of game interest. The analysis of the results allows identifying the decrease of the temporal consistency indexes, which is manifested in the prevailing emotionally personalized assessment of time restricting their ability to evaluate and plan time efficiently. We observed a very low level of development of motor coordination of children with general speech underdevelopment, which level is considered as the reflection of the probabilistic forecast on the level of motion anticipation. But the results of informative questions assessing the spatial element of anticipation consistency of the children with general speech underdevelopment are validly better than of the children in the control group. The obtained results enrich the understanding of psychological regularities of mental development of speech with the understanding of the required participation in this process of anticipation abilities, thus contributing to the theory of development psychology.
\end{abstract}

Keywords: Anticipation Anticipatory Consistency, Probabilistic Prognostication, Speech Pathology, General Speech Underdevelopment, Prognostic Activity

\section{INTRODUCTION}

Study of functional indicators of the children over five years of age is of special importance because by this age, the difference between the statistically normal development and deviation from it becomes obvious (Astapov, 1994; Wallin, 1955; Caplan and Sadock, 1989).

Currently, psychologists and teachers of secondary schools and child care settings note considerable growth of the number of claims on school underperformance or de-adaptation of primary school-aged children and their insufficient psychological readiness for schooling. Another fact draws our attention-the general assessment of the intelligence of a child in most cases can remain within the standard average age-specific indexes (Artemyeva, 2013). However, in the course of special research (defectological, neuropsychological), the attributes of certain extent of general speech retardation are often detected (Schrefebusch, 1997; Steinhausen, 1981). 
We find the effort to assess such psychological phenomena of the child mentality as the spatial and temporal elements of anticipation consistency of children of 6-7 years of age with general speech retardation timely and scientifically important.

Despite the extensive research in the sphere of anticipation and probabilistic forecasting, we failed to find any literary sources, which would have concerned the issue of formation of the anticipation and probabilistic forecasting processes with children who have general speech retardation.

Only occasional opinions on the peculiar features of probabilistic forecasting of normal children of 8-9 years of age and those who had mental abnormality are present in literary sources (Akhmetzyanova, 2013; 2014).

The materials that unveil the peculiarities of the probabilistic activity of children who progress in mastering the secondary school program with different success and the assessment of anticipation parameters and probabilistic forecasting of normal children and those who have neurotic disorders are represented (Mendelevich, 2003). Sergienko (1988; 1989) carried out a theoretical and experimental analysis of the elementary forms of anticipation (changes of the selectiveness and development of the spatiotemporal prediction) in the early ontogenesis of a human.

The research involved 140 children over five years of age, whose files contained (based on the results of examination by a psychological, medical and pedagogical commission) evidences of general speech retardation of third level (90 children). Preschool children of the same age (50 children) without any speech disorders were included in the control group.

The experimental research was carried out at the premises of a kindergarten in the groups of children without speech disorders and the groups of children with speech disorders. None of the examined children had any positive psychotic symptoms and severe neurological disorders.

The psychodiagnostic research was carried out at the premises of a kindergarten in the groups of children without speech disorders and the groups of children with speech disorders.

\section{RESULTS}

In the course of the research, it was revealed that children with the third level of general speech retardation had a vocabulary close to normal and they used extensive phrasal speech when communicating with the people around, did not have any difficulties in naming items, actions, attributes of items, which were very familiar to them from the ordinary life; they had essential cultural and hygienic skills, but the level of their mental development was below the agespecific normal value. Their distinctive attribute was the insufficient vocabulary related to the knowledge of the environment, low level of categorical generalization, difficulties at counting and painting.

Observations of the spontaneous play and educational activity showed that the behavior of the children in the experimental group differed considerably from the behavior of the children in the control group: They showed motor disinhibition, fussiness, could not choose an activity for a long time, focus on anything, or they failed to restrain their gushes, so they often conflicted with other children. Or, vice versa, they were overinhibitied, slow at any activity, ignored the surrounding reality, could stay for a long time doing nothing and showed inactivity.

In order to study the anticipation peculiarities of the children with general speech retardation, we modified the anticipation consistency test (test of predictive competence) (Mendelevich, 2003). We revealed and assessed the quantitative values of anticipation abilities by two elements: Spatial and temporal. The spatial element of the anticipation consistency demonstrates the abilities of a child to predict the motion of items in space, to anticipate them and to coordinate his moves showing motor coordination. The temporal element represents the ability of temporal prediction of events, structuring and orientation in time.

In order to study the chronorhythmologic peculiarities of children, we used the test of anticipation consistency modified for the children over five years of age. Using this instrument, we managed to study the abilities to predict the motion of items in space, to anticipate them and to coordinate one's moves showing motor coordination.

Taking into account the objectives of the research and, particularly, the assessment of the degree of motor coordination, which is considered as a reflection of probabilistic forecast on the level of motion anticipation, we used certain graphic methods applied for selection of children at entering the school. All tasks of the graphic test targeted detection of the development of fine motor skills of hands and coordination of vision and hand motion. The following tests were used at that: 
- The classical variant of the test for visual and motor coordination by A. Kern, which assumes a child to draw a man's shape, copy a phrase written in cursive letters and copy a group of dots

- The test of hand's readiness for writing by L.A. Wenger, which assumes drawing a line permanently touching the paper with the pencil and staying within the predetermined contours

The child's performance was assessed-the line precision, the number of disconnections from the paper sheet and trespasses beyond the contour, consistency of the copied elements with the source drawing. The results of the work were compared to the group of children who had normal speech.

The child's performance was assessed-the line precision, the number of disconnections from the paper sheet and trespasses beyond the contour, consistency of the copied elements with the master sample. The results of the work were compared to the group of children who had speech consistent with the age-specific standard.

These methodologies have sufficient reliability and validity. The examination was carried out individually, at the same time of day (in the first half of the day) and in the same environment (the psychologist's office in the kindergarten). With account for the age-specific peculiarities of children, the examinations did not last more than 20-25 min. At that, the psychologist took into consideration the state of children and as soon as she noticed any fatigue, she suggested to solve an easier task or to have a rest.

The procedure of the examination was not fixed. The psychologist watched the children not to lose interest; therefore, the experimental tasks were rotated and carried out quickly.

Besides, the implicit characteristic of the anticipation processes peculiar features was obtained at all other forms of the examination by analyzing how the child used the preliminary directions and how he changed his activity when the task's conditions changed.

\section{DISCUSSION}

According to the evidence of the data provided in the Table 1, valid differences between the values of temporal and spatial elements of anticipation consistency as well as the values of motor coordination of the children with general speech retardation and those of the children with speech development consistent with the age-specific standards were revealed.
Assessment of the characteristics of anticipation activity through the modified test of predictive competence showed valid differences in the group average values: The ability to act and take decisions with a certain spatiotemporal anticipation of future events of the children in the control group was validly better than the one of the children with general speech retardation (Akhmetzyanova, 2013). The typical feature of them was their inability to assess and plan the time. The time assessment was made by them based on emotional and personal perception-in one case the time rushed, in another it was catastrophically slow. This could be exactly the reason why the children in the experimental group demonstrated poor commitment. For example, when assumed sufficient time available for completing the task, they were anyway late every time due to their inability to coordinate the necessary manipulations with the assigned time. Thus, we can be assured that the temporal (chronorhythmologic) element of anticipation consistency of the children with general speech retardation deviated from normal, which is clearly evidenced by the results of the modified version of the Test for anticipation consistency $(\mathrm{PK})(\mathrm{t}=-3.892, \mathrm{p}<0.001)$.

The obtained results also evidence that the value of the spatial element of the predictive competence of children in the experimental group is validly higher than the values of the children in the control group $(\mathrm{t}$ $=9.622, \mathrm{p}<0.001$ ).

The parameter of motor coordination, which can be treated as another attribute of the human predictive competence efficiency with regard to the spatial element, validly differentiated children with general speech retardation from other children. The children in the experimental group typically showed worse results in spatial orientation; they often displayed motor incoordination. Their typical attribute was the frequent mistakes both in "orienting themselves with respect to the terrain" and in the "body scheme" (particularly, the typical feature of children with general speech retardation is their poor ability to distinguish the right and the left if compared to other children). These children had poor coordinate notion (the notion of items location using the "top-bottom" expression, the "to which side of the body" concept). The children with general speech retardation started using the prepositions describing the relative location of items with respect both to the body and to each other (in, above, under, in front of, etc.) later than the children with normal speech did. 
Table 1. Average values of test results of children with general speech retardation and standard speech development

\begin{tabular}{|c|c|c|c|c|}
\hline Indicators & $\begin{array}{l}\text { Experimental } \\
\text { group }\end{array}$ & Control group & t-criterion & $\begin{array}{l}\text { Validity of } \\
\text { differences, } p\end{array}$ \\
\hline Motor coordination & 35.02 & 60.50 & -9.578 & 0.01 \\
\hline Temporal element of anticipation consistency & 1.58 & 2.40 & -3.892 & 0.01 \\
\hline Spatial element of anticipation consistency & 4.48 & 3.10 & 9.622 & 0.01 \\
\hline
\end{tabular}

But the results of informative questions, which assess the spatial element of anticipation consistency of the children with general speech retardation, turned out to be validly better than those of the children in the control group (4.48 and 3.10 accordingly, $\mathrm{p}<0.001$ ). The explanation is that mistakes and failures made by the children with general speech retardation were excluded and ignored by them. Because of the infantile features, the mechanism of exclusion is ultimately fine-tuned and perfect (Frolova, 2014). It helps the children with general speech retardation to avoid thinking of something unpleasant, to notice something specific in the reality and to ignore something else, to see what they want to see ignoring the reality.

The spatial and temporal vision of the child is the basic prerequisite of ontogenesis of the mental activity, which is the basis of not only its cognitive, but also affective development. In its turn, formation of spatial and temporal vision is closely related to the timely development of motor activity. The development of spatial and temporal vision, spatial orientation in ontogenesis is the basis of the cognitive chain link of the higher mental functions (Minullina, 2014). The insufficiency of formation of spatial and temporal vision directly affects the level of actual intellectual development of a child, which phenomenologically manifests itself in the disorders of graphic activity, reading and writing, which is confirmed by our research (Akhmetzyanova, 2014).

In order to assess the degree of motor coordination, which is considered as a reflection of probabilistic forecast on the level of motion anticipation, we used certain graphic methods applied for selection of children at entering the school.

Analysis of the graphic tests results showed that children with general speech retardation committed the following mistakes: Uneven, poor drawing, extensive pressure, metric inconsistence (letters were magnified when copied), elementary disposition rigidities (multiple contouring, underlining letters, scaling down elements of the drawing). At the same time, the control group showed high and medium results of readiness of their hands for writing, more precise copying of the drawing elements and cursive letters.
The analysis of the visual and motor coordination development level of the children in the two groups showed the following results: Children with general speech retardation significantly more frequently demonstrated poor results $(\mathrm{t}=3.563, \mathrm{p}<0.001)$ and results below the medium level $(t=5.254, p<0.001)$, than children with the speech relevant to the age-specific standard values and the children in the control group considerably more frequently demonstrated good results $(\mathrm{t}=-8.509, \mathrm{p}<0.001)$.

Children with general speech retardation were also behind their normally developing peers at precise reproduction of motion tasks by the spatiotemporal parameters, failed to keep to the sequence of action elements and omitted its stages.

There are significant differences between the group of children with general speech retardation and the control group-the manual dexterity development values are significantly lower in the experimental group $(t=-9.578, p<0.001)$.

The obtained results also characterized the voluntariness of mental activity-the ability to control consciously one's actions and mental processes. Insufficient self-control at fulfillment of tasks was typical of the children with general speech retardation, they failed to keep to the rules and showed more interest in playing ("I will draw a car instead of a man", "I want to go off the path, let there be a crash", "I will first walk through the paths and then draw the letters", etc.) (Akhmetzyanova, 2013). Their attention exhausted very quickly, some children showed poor stability of attention and limited ability to distribute it. The children with general speech retardation changed the sequence of the suggested tasks. Often, they excused their failures by having forgotten the guidance, or simplified it ("I forgot, I thought I was to put many dots only", "I thought I was just to draw a little").

\section{CONCLUSION}

Generally, the substantial analysis of the obtained data confirmed the hypothesis that the general speech retardation, which is one of the most important factors determining the mental and personalized development 
and adaptation of a child of preschool age, is related to the disorder of anticipation parameters of mental activity. Many children in this group have the general motor incoordination; the formation of motor automatism is hindered with them. The immaturity of the emotionalvolitional sphere in the form of infancy, emotional lability and deficit of speech regulation of mental activity are registered. Generally, any activity type (game, communication, education) is non-productive.

The analysis of the results allows identifying certain peculiarities of anticipation activity of the children with general speech retardation in the form of the temporal consistency indexes decrease, which manifests itself in the prevailing emotionally personalized assessment of time restricting their ability to evaluate and plan time efficiently.

Very low level of development of motor coordination of children with general speech retardation was observed, which is considered as the reflection of the probabilistic forecast on the level of motion anticipation. But the results of informative questions, which assess the spatial element of anticipation consistency of the children with general speech retardation, are validly better than those of the children in the control group are.

Currently, psychologists and teachers of secondary schools and child care settings note considerable growth of the number of claims on school underperformance or de-adaptation of primary school-aged children, insufficient psychological readiness for schooling. It is necessary to study the connections and interdependencies of anticipation parameters of mental activity and general speech underdevelopment of various genesis at the senior pre-school age in view of the processes of adaptation and de-adaptation of a child.

Presently, we have developed and are now testing the program of development of anticipation particularities of children who have speech pathology.

\section{ACKNOWLEDGEMENT}

The authors acknowledge research advisor professor Vladimir Mendelevich. We are responsible for all errors as well as heavy style of the manuscript.

\section{REFERENCES}

Akhmetzyanova, A.I., 2013. The specifics of anticipatory consistency of children with speech pathology. Middle East J. Scientific Res., 16: 927931. DOI: 10.5829/idosi.mejsr.2013.16.07.11956
Akhmetzyanova, A.I., 2014. The development of selfcare skills of children with severe mental retardation in the context of Lekoteka. World Applied Sci. J., 29: 724-727. DOI: 10.5829/idosi.wasj.2014.29.06.13922

Artemyeva, T.V., 2013. Peculiarities of Primary School Children Figurative Speech Comprehension. World Applied Sci. J., 27: 738-741. DOI: 10.5829/idosi.wasj.2013.27.06.13709

Astapov, V.M., 1994. Research of peculiarities of predictive activity for dimension of intelligence level of children. International Pedagogical Academy, Moscow.

Caplan, H.Y. and B.J. Sadock, 1989. Clinical Psychiatry. 1st Edn., Baltimore, pp: 1-2.

Frolova, A.v., 2014. Peculiarities of predictive activity of persons who have neurotic disorders with various intensity of religious activity. World Applied Sci. J., 29: 1586-1590. DOI: 10.5829/idosi.wasj.2014.29.12.13985

Mendelevich, V.D., 2003. Test of anticipation consistency (predictive competence): Experimentally psychological method of assessment of readiness for neurotic disorders. Soc. Clin. Psychiatry, 3: 35-40.

Minullina, A.F., 2014. Research of anticipation consistency in the families of drug addicts. MiddleEast J. Scientific Res., 19: 1099-1103.

Schrefebusch, R.L., 1997. Language and mental retardation. empyreal and conceptual consideration. New York

Sergienko, E.A., 1988. Anticipation in visual behaviour of infants. Proceedings of the 11th European Conference on Visual Perception, United Kingdom in Perception, Bristol, pp: 1284.

Sergienko, E.A., 1989. Genesis of the elementary forms of anticipation in infants. Proceedings of the 10th Biennial Meeting of ISSBD, (ISSBD' 89), Jyvaskyla, pp: 387-387.

Steinhausen, H.C., 1981. Chronically ill and handicapped children and adolescents: Personality studies in relation. J. Abnormal Child Psychol., 9: 291-7. DOI: 10.1007/BF00919121

Wallin, A., 1955. Clinical and Abnormal Psychology. 1st Edn., Paris, pp: 274. 